ENCYCLOPÉDIE Encyclopédie berbère

BERBERE

$26 \mid 2004$

26 | Judaïsme - Kabylie

\title{
Kabylie : Art rupestre en Grande Kabylie
}

G. Lefebvre

\section{OpenEdition}

Journals

Édition électronique

URL : http://journals.openedition.org/encyclopedieberbere/1399

DOI : 10.4000/encyclopedieberbere.1399

ISSN : 2262-7197

\section{Éditeur}

Peeters Publishers

\section{Édition imprimée}

Date de publication : 1 mai 2004

Pagination : 3999

ISBN : 2-7449-0452-X

ISSN : 1015-7344

\section{Référence électronique}

G. Lefebvre, « Kabylie : Art rupestre en Grande Kabylie », Encyclopédie berbère [En ligne], 26 | 2004 document K05, mis en ligne le 01 juin 2011, consulté le 15 décembre 2020. URL : http:// journals.openedition.org/encyclopedieberbere/1399; DOI : https://doi.org/10.4000/ encyclopedieberbere.1399

Ce document a été généré automatiquement le 15 décembre 2020.

() Tous droits réservés 


\title{
Kabylie : Art rupestre en Grande Kabylie
}

\author{
G. Lefebvre
}

1 L'existence d'un art rupestre en Grande Kabylie est connue depuis plus de soixante ans et les inscriptions libyques peintes d'Ifigha signalées dès 1900 furent publiées par A. Boulifa en 1909.

2 Le nombre de stations actuellement connues est de 52. La plupart ont été découvertes par R. Poyto et J.-C. Musso. On les trouve dans des abris, sur des rochers et des blocs de grès de la partie Nord de la Kabylie. Elles comptent quelques gravures sur dalles et sur parois, et de nombreuses peintures conservées sur les parois des abris. Il est à peu près certain que toutes les œuvres sont protohistoriques sinon plus récentes.

3 Du point de vue esthétique, l'ensemble apparaît pauvre si on le compare à celui des autres régions de l'Algérie. On y reconnaît quelques silhouettes humaines et animales, généralement très frustes, des tracés linéaires, des bâtonnets, des pointillés, des ovales, des croix, des rectangles cloisonnés, des signes pectiformes et des caractères libyques en très grand nombre.

4 La peinture utilisée est l'ocre rouge naturel. Sa teinte varie : il peut être d'un rouge très vif, d'un rouge orangé, d'un brun rouge, d'un brun foncé, d'un brun violacé, d'un brun presque noir. La variété de ces teintes est encore accrue par le délayant qui permet dans chaque cas une infinité de nuances. Cependant, les couleurs sont toujours posées en teinte plate, parfaitement uniforme sur toute la surface décorée.

5 On peut constater, à la suite de R. Poyto et J.-C. Musso, dans l'art rupestre de Grande Kabylie « une pauvreté de l'inspiration artistique et une médiocrité de l'exécution » qui opposent ces œuvres à celles de l'Atlas saharien. 


\section{BIBLIOGRAPHIE}

Boulifa A., Notice sur l'inscription libyque d'Ifira (mission Haut-Sébaou). Rev. archéol., t. LIII, 1909, p. 411.

СНАВоТ J.-В., Recueil des inscriptions libyques. Imprim. nat. Paris, 1940, nº 848, p. 185.

MARCHAND Dr, «Stations préhistoriques littorales de la Grande Kabylie ». Bull. de la Soc. d'Hist. nat. de l'Afr. du N., t. XXV, nov. 1934, p. 335-348 (336).

PoYTo R. et Musso J.-C, Corpus des peintures et gravures rupestres de Grande Kabylie. Mém. XI du C.R.A.P.E., Paris, A.M.G., 1969.

INDEX

Mots-clés : Art rupestre, Kabylie, Protohistoire 